\title{
Informal Learning of Thai Chinese in Songkhla Province through Qingming Tradition
}

\author{
Buakaew Jureerat ${ }^{1} \&$ Janjula Jiraporn ${ }^{1}$ \\ ${ }^{1}$ Faculty of Liberal Arts, Prince of Songkla University, Songkhla, Thailand \\ Correspondence: Buakaew Jureerat, Faculty of Liberal Arts, Prince of Songkla University, Songkhla, Thailand. \\ Tel: 66-74-28-6751. E-mail: jureeratana.k@psu.ac.th
}

Received: December 3, 2013 Accepted: January 6, 2014 Online Published: January 27, 2014

doi:10.5539/ass.v10n3p138

URL: http://dx.doi.org/10.5539/ass.v10n3p138

\begin{abstract}
This qualitative study aimed to investigate the informal learning of Thai Chinese in Songkhla Province through Qingming tradition. The data were collected from in-depth interviews and participatory observations with 30 subjects who were Thai Chinese.

The results of the study revealed that Thai Chinese in Songkhla Province learn Quingming tradition through adults in their family since they were children. Adults teach, practice and take children with them to perform rituals on Qingming Day. Children take part with interest and when they grow up and become teenagers, they participate in the tradition by helping to prepare items that are used in worshiping their ancestors. When they become adults and have a career to earn a living, they are assigned to prepare all the worship items for the rituals every year as their parents get old. Thus, this is the way Qingming tradition is learned by Thai Chinese; they learn it informally as the tradition is passed down from one generation to the next. Therefore, new generations of Thai Chinese will continue learning this tradition into the future and this helps keeping it in Thai society.
\end{abstract}

Keywords: informal learning, Thai Chinese in Songkhla Province, Qingming tradition

\section{Introduction}

Economic and political crises during the reign of the Qing dynasty (A.D.1635-1911) caused competition for power, corruption, foreign intervention, and natural disaster (Phongphaibun, 1997) resulted in hardships for Chinese and some of them decided to leave their home country and migrate to other countries to seek fortune and better life, a condition known among people in Thailand as "One mat and a pillow". The Southern part of Thailand was a region popular among Chinese merchants for trade and settlement during the 18-22 centuries as it was a trading port since the old days. Therefore, traveling by large junks to Thailand from China for trade was easy. In the beginning, newly arriving Chinese would do anything when hired such as being coolies at a port, rice mill, mine, and selling things.

Songkhla was a place popular among Chinese, especially the Hokkian Chinese who came in to live there since the end of the Ayutthaya Period because Songkhla's location was suitable for being a trading port that large ships could come in to the inner part near the beach where the sea was deep (National Library of Thailand, Phra Kalahom's Official Affairs, the Reign of King Rama IV (1859), Krom Phraya Phanuphanthuwong Woradet, 1961). In addition, Chinese knew how to adapt to Thais, were determined, patient, and knew how to save up their money. Some of them became rich and could buy land and build houses to live in Thailand permanently. Others moved their status upwards to the political system and were promoted to high positions. One example is, Mr. Yiang Sae How (an ancestor of the family name Na Songkhla) who was appointed the ruler of Songkhla. He was originally from Jiang Province, Hiteng District, Santhong village. He migrated to Songkhla and settled near Hua Khao Daeng. In 1750, he was the tax farmer for bird nests on Ko Si and Ko Ha islands during the Dhon Buri Period. One year later he became Luang Suwankhirisombat and appointed the ruler of Songkhla in 1775. Eight of his descendants became rulers of Songkhla (Kaewmueng, 1986). Songkhla was very prosperous during the time when descendants of Na Songkhla were rulers. Chinese have always played important roles in trade in Songkhla and have promoted Songkhla to be increasingly prosperous with more Chinese and other foreigners migrating to do business and to live there.

When the Chinese came to settle in Songkhla, they tried to adapt to Thai society. Some were married to Thais 
and changed their surname into Thai; however, they still preserve their traditions and culture very well and pass their Chinese identities down to their descendants continuously until today (Roy, 1966). Therefore, the roles played by the Chinese are important for us to study about how they pass down their concepts and beliefs continuously to their Chinese Thai descendants. This study, therefore aimed to investigate informal learning of Chinese Thai in Songkhla Province particularly how they pass down their traditions and culture through Qingming tradition. Qingming is a tradition in which Chinese gives importance to paying respect to their ancestors. They believe that if they pay respect incorrectly, they will not be successful in their work life. Thus, it is a tradition that reflects gratefulness the Chinese have towards their ancestors. It is also a time for a family reunion as well as a time when they pass down the belief to the younger generations. It is interesting to see how the belief is passed down in the age of globalization.

\section{Objective}

This study aimed to investigate informal learning of Chinese Thai in Songkhla Province through Qingming tradition.

\section{Definitions of Terms}

Informal learning refers to knowledge transfer by actual doing that develops to transmission to later generations by demonstration and teaching by ancestors, father, mother, and elderly relatives (Na Thalang, Ekawit, 1997).

Chinese Thais refers to younger generations of Chinese or Chinese who have Thai nationality according to the Thai nationality law and live in Songkhla Province.

Qingming tradition refers to the tradition of paying respect to ancestors of Thai Chinese in Songkhla Province that is held on yearly on the $5^{\text {th }}$ of April with the ceremony taking place at the ancestral burial ground or Huang Sui.

\section{Research Method}

The data of this qualitative study were collected through in-depth interviews and participatory observations in Qingming tradition. The research design is as follows:

1) Selection of the study areas-Songkhla Province was selected because it is an area where Chinese with problems of poverty migrated to make a living in the reign of King Rama III, and settled there permanently. Their descendants have lived in this area until now. Hat Yai, Na Thawi, Singha Nakhon, and Sadao were districts in Songkhla Province selected for field data collection.

2) Informants-Thirty informants were divided into three age groups. Ten teenagers in the age range of 19-24 years; 10 work age in the age range of 25-40 years, and 10 adults in the age range of over 41 years.

3) Data analysis-The data collected from documents, in-depth interviews and participatory observations were analyzed using a historical method, Na Thalang's (1997) concept in beliefs, and Bruner's (1966) theory of knowledge building as the main tools to describe the phenomenon of informal learning of Thai Chinese in Songkhla Province through Qingming tradition. Then analytical description was carried out.

\section{Results}

There are two methods used in the informal learning of Thai Chinese in Songkhla Province about Qingming tradition as follows:

\subsection{Storytelling}

Chinese ancestors who traveled across the sea to settle in Songkhla Province tell their descendants stories about themselves and their traditions so that their descendants can practice in the same way. This is how Chinese traditions are instilled in the younger generation in order to maintain them.

1) The rituals in Qingming tradition that Thai Chinese in Songkhla Province hold on to practice continually are held during April 1- 5 of the year. They can choose the day that is the most convenient for them in order to gather the highest number of relatives on the day as said by Sisuk Pranee (interviewed on November 4, 2013).

"Everyone comes to see each other to realize that they have the same ancestor. I have many children and grandchildren and all of them must come so that they know that we come from the same family. It is like a reunion of family members where we can talk and ask about how they are. Some live far away from here and we seldom see them so this is the time that we meet and unite among our relatives."

Therefore, Qingming Day is a good opportunity for children and relatives to meet again and the following is the steps of practice. 
"Before Qingming Day arrives, everyone helps clean the burial grounds. Relatives help prepare food and things used to pay respect to ancestors. On Qingming Day, we go to the burial grounds of our ancestors early in the morning. We begin the day by taking with us food, rice, desserts and fruits to the front of the Sinchu or ancestor's shelf to tell our ancestors that today is "Qingming Yit" or the day for Qingming rituals. After that we pay respect to the guardian spirits of the cemetery before paying respect to our ancestors. The food and worship items include five meat dishes, one bottle of rice whiskey or tea, and five joss sticks. After paying respect before the tomb of Pae Kong, we pay respect to the tombs of our ancestors with offering items of chicken, pork, duck, rice, other food, and at least five kinds of fruit. So we begin from paying respect to the guardian spirit of the graveyard and then to our ancestors. (Chongcharoenyingthawon Churairat, interviewed on November 4, 2013). (See Figure 1).

Everyone who comes to take part in the Qingming rituals helps arrange the worship items. Descendants bring rainbow-colored paper, colorful glitter pieces, small flags in different colors, flowers to spread on the grave as a sign to say that descendants have come to pay respect. We also clean our houses for our ancestors to see that our houses are beautiful. (Suthiwong Surangrat, interviewed on November 4, 2013). (See Figure 1).

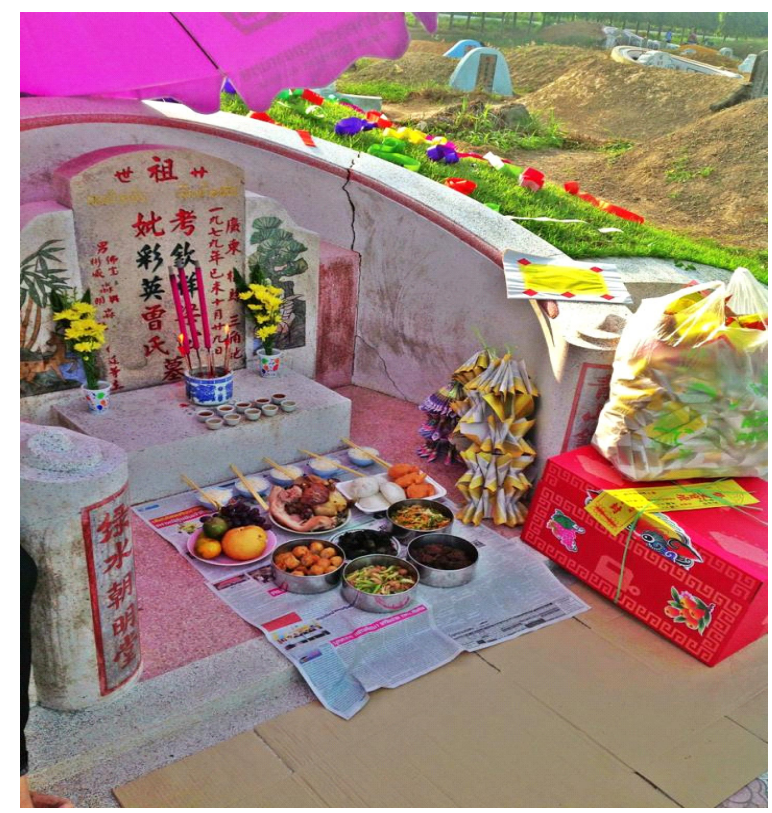

Figure 1. Paying respect before the burial site of ancestors on Qingming Day

Source: photo by researcher at cemetery, Tambon Phangla, Sadao District, Songkhla Province on April 5, 2013

After paying respect, we wait until the joss sticks nearly finish burning. Then we begin to burn silver paper, gold paper, a box of clothes, Kong Tek money or faux cash and other items of paper utensils so that our ancestors can use them in their world. After that we light firecrackers to tell our ancestors that their descendants have come to pay respect. (Chonwatthanaphaibun Wanna, interviewed on November 6, 2013). After that members of each family sit in a circle to have lunch and talk together on the space in front of the grave before going back home. In Songkhla Province, there are several large cemeteries but the most well-known ones are the one in Tambon Ban Phru, Hat Yai District, and the other in Tambon Phangla, Sadao District, Songkhla Province.

2) Significance of Qingming tradition-Chinese Thai give importance to family relationships and use traditions as means in tightly networking as can be seen from the interviews with the elderly and the working age group.

"Descendants can have a reunion; everyone should come, if possible because it is an auspicious occasion. I tell everyone to come to pay respect to our ancestors, to our fathers and mothers." (Chaitrong Onsi, interviewed on November 6, 2013).

"We've done it since the time of our grandfathers and grandmothers. It's a way of paying respect to our ancestors that we do regularly every year." (Phatthana-amon Phiphat, interviewed on November 6, 2013).

"It's also an important family reunion day." (Chonwatthanaphaibun Wanna, interviewed on November 6, 2013).

"And we can teach our children to respect their ancestors and for them to get to know their relatives who 
participate in the rituals" (Olanukhro Pornphan, interviewed on November 8, 2013).

3) Instilling a belief about the next world-This is done by preparing the best kinds of food that one can afford to bring to the rituals, as well as bringing paper items to burn such as silver paper, gold paper, clothes, cars, houses, servants, cell phones, etc. so that our ancestors can use them and will not be in hardships (Wongsirichot Rattana, and Kiattumaphan Surirat, interviewed on November 16, 2013). All food used in the rituals have good meanings. For example, Khanom Thuaifu has an auspicious name meaning prosperity. Thus, the descendants will be prosperous and progressive in their work position. Large pieces of Tofu represent promotion in position and prestige; the descendants will become masters or heads of people. Fruits that are popular for the rituals include orange because its name is auspicious meaning being great, and representing good luck and friendship. Banana means passing or going through easily with convenience, without obstacles, and having many children. Fruits that are not suitable for the rituals include pear as it is believed that it can make the soul of the deceased return and not be able to be reborn. Mangosteen has an inauspicious name, and thus, obstructs progress or advancement.

In addition, firecrackers are lit to make a loud noise in order to tell the ancestors that their descendants have come to visit and have brought them food and other things, and to ask them to come and receive them and give their descendants blessings so that they are happy and prosperous. When rainbow-colored paper and, colorful glitter pieces are spread over the grave instead of flowers, it means for descendants to be wealthy (Suthiwong Surangrat, interviewed on November 16, 2013).

4) Instilling a belief about gratefulness-The purpose of Qingming tradition is to worship ancestors and to show gratefulness or gratitude to the deceased ancestors. Thai Chinese in Songkhla Province believe that paying gratitude to their ancestors by worshiping them is an expression of gratefulness according to Confucius, and it will make their family happy and successful because their ancestors will protect them all the time, as said by an elderly respondent.

"It's an expression of gratitude towards your ancestors; it's a tradition that has been around for many generations." (Sae Lim Kanda, interviewed on October 18, 2013).

"For descendants to be prosperous, they must be grateful to their ancestor." (Olanukhro Pornphan, interviewed on November 6, 2013). Teenagers also see it is important "because it's the time to pay respect to our ancestors, I have to go every year." (Yongyutwutthikun Supawi, interviewed on November 6, 2013).

\subsection{Practice and Participation of Descendants in Qingming Tradition}

Every year Chinese Thai in Songkhla Province prepare worship items for the rituals with good intention, dedication and they take it as important to show gratitude to their ancestors. So they come to participate even though they live far away. In some family, the practice began by their grandparents, and when their grandparents passed away, their parents continued the practice, and when their parents passed away, they themselves continue the practice. This can be seen from the following excerpts.

"I teach my children to help me prepare the worship items and take them to the rituals every year." (Phatthana-amon Phiphat, interviewed on November 6, 2013).

"I always pass the tradition down to my children indirectly. I do it for them to see and let them help in preparing the worship items since they were very young. It's an activity that everyone in the family helps with what they can." (Chitcham Sopha, interviewed on November 5, 2013).

"I go there every year. I mainly teach my oldest daughter while the younger ones participate the rituals every year. We distribute work for everyone to help." (Chongwatthanaphaibun Wanna, interviewed on November 6, 2013).

"I take my children and grandchildren to participate in the rituals every year, and I distribute work for everyone to do, to take part, especially my oldest daughter and my oldest granddaughter. I try to transfer all the methods by explaining to them while doing it. I show them how to do it and sometimes I ask them to do it by themselves." (Olanukhro Pornphan, interviewed on November 8, 2013).

For Chinese Thai teenagers in Songkhla Province, they are taught and they do it the way their parents and relatives do, and it has become part of their way of life, as evidenced in the following interview excerpts.

"It's important because it's ancestral worship. My family does it every year. I have to help my mother do it. My mother tells me what to do and how to do it. I'm taught by my mother; she tells me what she wants me to do." (Densuriyaphrom Kasina, interviewed on November 6, 2013).

"It's important because it's paying respect to thank our ancestors. I must go every year because my mother orders 
me to go. She orders me to help since I was young. I go to the market with her, help her cook and prepare things and she explains to me while doing it." (Ratiwisakun Nanthika, interviewed on November 10, 2013).

"It's important because it's paying respect to our ancestors. The elderly tell us to do and to go to participate in the ceremony every year to show our gratefulness and to get acquaintance with our relatives, too." (Tertthatsanai, Sasithon, interviewed on November 6, 2013).

“It's very important because it is to show gratefulness to our ancestors. I must go every year. Even though I don't know really know how to do it, I know that the tradition must be there and what to use in the ceremony because I have seen my mother do it all along and I think that when it comes to my generation to do it, I'll continue doing it. (Chaitrong, Natcha, interviewed on November 6, 2013).

It can be seen that Thai Chinese in Songkhla Province are determined in performing Qingming rituals and pass it down to their children through informal learning. As a result, this tradition is maintained in the society of Songkhla Province.

\section{Discussion}

\subsection{Informal Learning of Thai Chinese in Songkhla Province through Qingming Tradition}

Qingming tradition is based on the importance given to gratitude towards ancestors and therefore, the tradition has always been informally transferred to Thai Chinese in Songkhla Province and they have participated in the rituals of the tradition since they are young until they become heirs of the tradition later in life. This corresponds with Bruner's (1966) theory that knowledge is built from experience of learners who are in the actual environments; learning is a process that learners create new concepts or follow the concepts existing in the past or the present. It also corresponds with the concept of Bunchuai (1989) who claims that learning causes experience that can be applied creatively or that can change attitude, and value. Knowledge transfer from actually doing it can develop to transmission to the later generations through demonstration, teaching, and telling which is called oral tradition.

\subsection{Transfer of Gratitude towards Ancestors}

Thai Chinese in Songkhla Province are taught from when they are young and they, therefore, accumulate successful experience in their career and transfer such belief to their children. This is in agreement with $\mathrm{Na}$ Thalang (1997) who states that beliefs are important for our existence and can influence society. They designate people' behavior and when people believe in something, it can make them do whatever responds to that belief. Praphaphitthayakon et al. (1987) refer to belief as something that a society has done for a long time from one generation to the next until it has become a pattern or guideline that people in that society follow. According to Atthakon (1977), a belief can result in performance of rituals that people do from one generation to the next and eventually becomes a tradition.

Beliefs in ancestral spirits such as those of deceased parents and grandparents that they are still around to protect their descendants lead to ancestral worship such as ancestral worship in Qingming tradition performed by Thai Chinese in Songkhla Province. They do it because they believe that it gives them confidence and ability to create work. Inspiration is needed to direct them to gain success in life. This is in agreement with Chongrakwong (1999) who says that beliefs are useful or important to people's existence and they have influence on society as they designate people's behavior.

It can be seen that these beliefs have become part of life for Thai Chinese in Songkhla Province who teach and show their children every year until eventually the children can do it, and the beliefs have become an important tradition for them.

It can be said that Chinese Thai elderly and those in the working age group who believe in gratitude towards their ancestors have transferred the belief, kinship relationship, building love, commitment, and unity to their children, the new generation through informal learning about Qingming tradition. This has become instillation of concepts and practice in Chinese Thai society in Songkhla Province until the present time. This corresponds with the concept of Siriphaisan et al. (2009) that culture of the Chinese in Hat Yai makes their way of life and social activities different from that of other groups of Thais in the area. Chinese in Hat Yai try to maintain their being Chinese strictly by using various processes such as using the Chinese language to communicate in their group, focusing interaction in their group in terms of work, creating kinship relations, and supporting their children to maintain Chinese traditions and thoughts.

Thus, Thai Chinese have identities that are different from other groups of Thais, especially their gratefulness to their ancestors, and love for people in their groups of family and friends that can be seen from the number of 
groups and activities. There are various Chinese ethnic groups and Chinese foundations that emphasize maintaining their being Chinese, building good relationships and proving help among Chinese ethnic groups. These factors are important elements that make the way of life of Thai Chinese outstanding, result in success in life and their ability in preserving Qingming tradition for later generations.

\section{Conclusion}

It can be concluded that Thai Chinese in Songkhla Province attach importance to gratitude towards their ancestors in accordance with Confucius concept in that people who worship their ancestors will be successful in the career and become wealthy. Thus, they transfer their belief about ancestral gratitude to their children by teaching, practicing, and allowing their children to participate since they are young. They do it every year and it has become an important tradition with respect paying rituals. Therefore, the passing down of Qingming ritual is a form of informal learning that is passed down continually from one generation to the next.

\section{References}

Atthakon, K. (1977). Folklore. Bangkok: Teachers Council of Thailand Press.

Bruner, J. S. (1966). Toward a Theory of Instruction. Massachusetts: Belkapp.

Bunchuai, C. (1989). Beliefs Appearing in Rituals of Chinese Thai in Mueang Songkhla District, Songkhla Province. A thesis for Master of Arts. Songkhla: Srinakharinwirot University, Southern Part.

Callista, R. (1966). An Understanding of Roy's Adaptation Theory. Los Angeles: University of California.

Chongrakwong, N. (1999). Food Used in Yearly Traditions of Thai Chinese in Hat Yai City Municipality, Hat Yai district, Songkhla Province. A thesis for Master of Arts. Songkhla: Thaksin University.

Kaemkhunthot, C. (2001). A Study of Yearly Traditions of Thai Chinese in Phuket Municipality, Mueang Phuket District, Phuket Province. A thesis for Master of Arts. Songkhla: Thaksin University.

Kaewmuang, D. (1986). Chinese: People and Culture in the Southern Part. Encyclopedia of Southern culture (Vol. 9). Bangkok: Amarin.

Na Thalang, E. (1997). Folk Wisdom from the Four Regions. Nonthaburi: Sukhothat Thammathirat.

Phongphaibun, S. (1997). Research Report on Thaksin Chinese: Way and Energy. Bangkok: The Thailand Research Fund (TRF).

Prachum Phomgsawadan, Volume 3 (Part 3). (1963). Bangkok: Teachers Council of Thailand Press.

Praphaphitthayakon et al. (1987). Language and Culture. Bangkok: Aksorncharoenthat.

Siriphaisan et al. (2009). Social and Cultural Change of the Chinese Community in Hat Yai from the Past to the Present. Bangkok: Office of the National Culture Commission.

The National Library of Thailand. Phra Kalahom's Official Affairs 1221 (B.E. 2402). Volume 17, p. 82.

Wachirayan Library. King Rama IV Archive Cho. So. 1222 (B.E. 2403). No. 114.

Woradet, K. P. (1961). Chiwiwat. Bangkok: Teachers Council of Thailand Press.

\section{Appendix}

\section{Informants}

Chaitrong, Natcha. (2013, November 6). Interviewee, $153 \mathrm{Mu}$ 1, Tambon Lamphai, Thepha District, Songkhla Province, 18 years old.

Chaitrong Onsi. (2013, November 6). Interviewee, $153 \mathrm{Mu}$ 1, Tambon Lampai, Thepha District, Songkhla Province, 49 years old.

Chitcham Sopha, (2013, November 5). Interviewee, 311/26 Mu 6, Tambon Thungyai, Hat Yai District, Songkhla Province, 52 years old.

Chonwatthanaphaibun Wanna. (2013, November 6). Interviewee, 83/193 Mu 3, Soi 21 Kanchanawanit Road, Tambon Khohong, Hat Yai District, Songkhla Province, 65 years old.

Densuriyaphrom Kasina. $4^{\text {th }}$ year student of Faculty of Management Sciences. (2013, November 6). Interviewee, 20 Sakhon Mongkhon 2 Road, Soi 9, Hat Yai District, Songkhla Province, 21 years old

Kiattumaphan Surirat. (2013, November 16). Interviewee, 19 Chanuthis Road, Nathawee District, Songkhla 
Province, 54 years old.

Olanukhro Pornphan. (2013, November 8). Interviewee, 472/6 Kopkun Uthit 4, Tambon Phangla, Sadao District, Songkhla Province.

Phattana-amon Phiphat. (2013, November 6). Interviewee, $153 \mathrm{Mu}$ 1, Tambon Lamphai, Thepha District, Songkhla Province, 76 years old.

Ratiwisakun Nanthika. $2^{\text {nd }}$ year student of Faculty of Management Sciences. (2013, November 10). Interviewee, 40 Soi 6/2, Phetkasem Road, Hat Yai District, Songkhla Province, 19 years old.

Sae Lim Kanda. (2013, October 18). Interviewee, 182/19 Mu 1, Tambon Khuan Lang, Hat Yai District, Songkhla Province, 74 years old.

Sisuk Pranee. (2013, November 4). Interviewee, Ranot Market, Ranot District, Songkhla Province, 64 years old.

Tertthatsanai, Sasithon. (2013, November 6). Interviewee, 7 Mu 5, Soi Kuansato 2, Kanjanavanit Road, Tambon Pangla, Sadao District, Songkhla Province, 19 years old.

Wongsirichot Rattana. (2013, November 16). Interviewee, 311/27 Mu 6, Tambon Thungyai, Songkhla Province, 51 years old.

Yongyutwutthikun Supawi. $3^{\text {rd }}$ year student of Faculty of Liberal Arts. (2013, November 6). Interviewee, 31 Thesaban 4, Tambon Phatong, Hat Yai District, Songkhla Province.

\section{Copyrights}

Copyright for this article is retained by the author(s), with first publication rights granted to the journal.

This is an open-access article distributed under the terms and conditions of the Creative Commons Attribution license (http://creativecommons.org/licenses/by/3.0/). 